\title{
Prognostic significance of TMEM16A, PPFIA1, and FADD expression in invasive ductal carcinoma of the breast
}

\author{
Eun Ji Choi ${ }^{1}$, Jeong A Yun ${ }^{1}$, Sahrish Jabeen ${ }^{1}$, Eun Kyoung Jeon ${ }^{2}$, Hye Sung Won², Yoon Ho Ko ${ }^{2}$ \\ and Su Young Kim ${ }^{1 *}$
}

\begin{abstract}
Background: 11 q13 region is a frequently amplified locus in human malignancies. Among the genes located in this region, FADD is one of the alleged driving genes. Because amplification is not generally confined to a single gene and amplified genes may not show increased expression, we need to evaluate clinical significance of changes occurring in 11q13 region to understand their roles in carcinogenesis. Therefore, we screened expressions of FADD and closely located genes (PPFIA1 and TMEM16A) and evaluated the expressions to find clinical significance in invasive ductal carcinoma of the breast.

Methods: Ninety-eight cases of invasive ductal carcinoma of the breast were collected. Using archival tissues resected from the cases, we built a tissue microarray and used it in immunohistochemistry. We evaluated the association of FADD, PPFIA1, and TMEM16A expression scores with clinicopathological parameters, including disease-free survival.

Results: FADD expression was associated with T stage $(P=0.046)$. The combined score of FADD, PPFIA1, and TMEM16A gene expressions was associated with perineural invasion $(P=0.022)$. Although individual gene expressions of TMEM16A, FADD, and PPFIA1 failed to show significant association with disease-free survival, combined gene expression scores did show association with disease-free survival $(P=0.034)$.
\end{abstract}

Conclusions: FADD, TMEM16A, and PPFIA1 gene expressions as a whole were associated with disease-free survival in breast cancer.

Keywords: TMEM16A protein, PPFIA1 protein, FADD protein, Carcinoma, Ductal, Breast

\section{Background}

Amplification is one of the activating mechanisms of proto-oncogenes during carcinogenesis [1]. Among the frequently amplified regions in human malignancies, amplifications of $11 \mathrm{q} 13$ were found in breast cancers [2-4], esophageal squamous cell carcinoma [5], and head and neck cancers [6-9]. In this region, several genes were located and the amplified region encompassed more than one of the tested loci [3]. In addition, region q13 of chromosome 11 was pointed out to have a high penetrance gene for breast cancer in the study of 19 nonBRCA1/2 families [10]. However, amplification does not

\footnotetext{
* Correspondence: suyoung@catholic.ac.kr

'Department of Pathology, The Catholic University of Korea, School of Medicine, Seochogu Banpodaero 222, Seoul 137-701, South Korea Full list of author information is available at the end of the article
}

necessarily result in increased expression of the affected gene. Taking into account that gene products rather than the genes themselves are effector molecules controlling biological behavior of the cells, we need to know the expression changes of the genes located in 11q13 and their clinical significance to understand their contribution to tumor cell behavior.

Among the genes located in the region of 11q13, FADD was reported as a driver in the 11q13 amplicon in laryngeal/pharyngeal cancer [11]. FADD is an adaptor molecule interacting with many kinds of death receptors and induces apoptosis by caspase-8 $[12,13]$. FADD expression was associated with metastasis in squamous cell carcinoma of the head and neck [14] and poor prognosis in oral squamous cell carcinoma [15] and lung adenocarcinoma [16]. Because the amplification of FADD does 
not confined in a single gene, TMEM16A or PPFIA1, which are in close proximity to $F A D D$, may be amplified concomitantly. In addition, the BAC clone (RP11$203 \mathrm{~N} 8$ ), which is used as a template when synthesizing the fluorescence in situ hybridization (FISH) probe for $F A D D$, includes the regions of TMEM16A and PPFIA1. Confirmation of amplification by FISH cannot differentiate copy number alterations among the genes. The locus encompassing these three genes is amplified in several malignancies, including breast cancer [17].

TMEM16A is associated with activation of the calcium dependent chloride channel and regulates cell proliferation [18,19]. TMEM16A is considered to be proto-oncogenic and increases tumor growth when overexpressed in gastrointestinal stromal tumors [20], and head and neck cancer [18]. Previous reports claimed that the calcium chloride channel influenced the growth of tumors and loss of $T M E M 16 A$, leading to decrease in tumor size [18,21]. However, the mechanism of tumor growth by TMEM16A overexpression is not known [22].

PPFIA1 is a member of the LAR protein-tyrosine phosphatase-interacting protein family. PPFIA1 is amplified in human breast cancers and promotes invasiveness of breast and cervical cancer cells [23]. Also, PPFIA1 acts as a tumor suppressor and regulates cell motility by interacting with ING4 [24]. When expression of PPFIA1 was reduced, invasiveness of head and neck squamous cell carcinomas (HNSCC) was found to increase [25].

Although TMEM16A, FADD and PPFIA1 are coamplified in many malignancies, the combined effect of the three gene expressions has not been evaluated to date. To understand the net effect of these three gene alterations, we screened the gene expressions by immunohistochemistry and analyzed the association with clinicopathological parameters, including disease-free survival.

\section{Methods}

\section{Patients and tumor tissues}

We collected 98 cases of invasive ductal carcinoma surgically resected at Uijeongbu Mary's Hospital from 2002 to 2004. Patients' age was between 29 and 77 (mean, 49.1) years old. Forty-six cases were treated with adjuvant chemotherapy and 33 cases received hormone therapy. Adjuvant radiotherapy was given to 22 cases. Disease-free survival data (11.0 to 103.3 months; mean, 61.9 months) was available. The disease recurred in 21 cases and 7 cases died of the disease. We selected representative archival tissues resected from the cases and tissue microarray was constructed using manual tissue arrayer, MTA-1 (Estigen Tissue Science, Estonia). Human tissue acquisition and its use followed the Institutional Review Board-approved protocol (CUMC11U058) at the Catholic University of Korea, School of Medicine.

\section{Immunohistochemistry}

The immunohistochemical staining of breast cancer tissue followed the previously reported protocol [26]. Briefly, tissue sections were cut in 4- $\mu \mathrm{m}$ thicknesses and transferred to ProbeOn Plus slides (Fisher Scientific, Pittsburgh, PA, USA). To minimize tissue loss during boiling procedure and to get rid of excess paraffin on the slides, tissues were incubated for two hours in a $56^{\circ} \mathrm{C}$ dry chamber (Agilent Technologies, Santa Clara, CA, USA). The sections were deparaffinized in xylene three times and hydrated through 100\%, 90\%, 80\%, 70\% ethanol and Trisbuffered saline (TBS, pH 7.4). To make the epitopes more accessible to the primary antibodies used in the current study, the tissues were boiled in $10 \mathrm{mM}$ sodium citrate buffer ( $\mathrm{pH}$ 6.0) using a microwave for 20 minutes. To quench endogenous peroxidase, we treated the tissues with 3\% hydrogen peroxide in PBS. The tissues were incubated with the respective primary antibodies at $4^{\circ} \mathrm{C}$ overnight (Table 1). After incubating the tissue with biotinylated secondary antibody, diluted (1:50) ExtrAvidin (Sigma-Aldrich, St. Louis, MO, USA) was used to amplify signal intensity. For visualization, liquid $\mathrm{DAB}+$ substrate chromogen system (Dako, Glostrup, Denmark) was used. Scoring of immunohistochemical staining was divided into three groups. Positive staining in less than $5 \%$ of tumor cells was considered negative. Cases showing a brown color in more than $50 \%$ of tumor cells were considered to be a strongly positive group. Cases showing light brown color in more than $5 \%$ and dark brown color in less than $50 \%$ of tumor cells were counted as a weakly positive group $[14,20]$.

\section{Statistical analysis}

Where appropriate, the Chi-square test or Fisher's exact test was used to evaluate association of immunoreactivity with clinicopathologic parameters. For diseasefree survival analysis, Kaplan-Meier method and the nonparametric log-rank test was used. We used $\mathrm{R}$ ver. 3.0.2 (R foundation, Vienna, Austria) for statistical tests and their graphic presentations.

\section{Results}

\section{Patient characteristics}

Among 98 cases in total, 5 (5.1\%) cases of grade I, 51 $(52.0 \%)$ cases of grade II, and $40(40.8 \%)$ cases of grade III were included in this study. Two (2.0\%) cases did not

Table 1 Primary antibodies used in immunohistochemistry

\begin{tabular}{lllll}
\hline Target & Dilution ratio & Host & Clone & Provider \\
\hline PPFIA1 & $1: 100$ & Rabbit & & $\begin{array}{l}\text { Proteintech } \\
\text { (Chicago, IL, USA) }\end{array}$ \\
TMEM16A & $1: 1$ & Rabbit & SP31 & Abcam (Cambridge, UK) \\
FADD & $1: 10$ & Rabbit & EP887Y & Abcam \\
\hline
\end{tabular}


have information on grade status. T1, T2, and T3 stages were 23 (23.5\%), 64 (65.3\%), and 11 (11.2\%) cases, respectively. For nodal stages, N0 (41 cases, 41.8\%) and N1 (34 cases, 34.7\%) were most common. Estrogen receptor (ER) was positive in 63 cases and progesterone receptor (PR) was positive in 65 cases (Table 2). ER and $\mathrm{PR}$ positivities of nine cases were not known.

\section{TMEM16A, FADD, and PPFIA1 immunoreactivity}

TMEM was positive in 86 cases (strongly positive 5 cases, weakly positive 81 cases). FADD was positive in 62 cases (strongly positive 3 cases, weakly positive 59

Table 2 The pathological parameters of the patients

\begin{tabular}{ll}
\hline Pathological parameters & $\begin{array}{l}\text { Number of cases } \\
\text { (total 98 cases) }\end{array}$ \\
\hline Age & \\
$<50$ & 59 \\
$\geq 50$ & 39 \\
\hline Grade & \\
I & 5 \\
II & 51 \\
III & 40 \\
\hline Tstage & \\
T1 & 23 \\
T2 & 64 \\
T3 & 11 \\
\hline
\end{tabular}

$\mathrm{N}$ stage

$\begin{array}{ll}\text { N0 } & 41 \\ \text { N1 } & 34 \\ \text { N2 } & 17 \\ \text { N3 } & 6\end{array}$

Estrogen receptor (ER)

$\begin{array}{ll}\text { Negative } & 26 \\ \text { Positive } & 63 \\ N A^{a} & 9\end{array}$

Progesterone receptor (PR)

\begin{tabular}{ll} 
Negative & 24 \\
Positive & 65 \\
$N A^{a}$ & 9 \\
\hline
\end{tabular}

\begin{tabular}{ll}
$\mathrm{NA}$ & 9 \\
Positive & 19 \\
Negative & 71 \\
$\mathrm{NA}^{\mathrm{a}}$ & 8 \\
\hline $\mathrm{LVI}$ & \\
Positive & 65 \\
Negative & 29 \\
$N A^{a}$ & 4 \\
\hline
\end{tabular}

${ }^{a} \mathrm{NA}$ : not available. LVI, lymphatic vessel invasion; PNI, perineural invasion. cases). PPFIA1 was positive in 88 cases (strongly positive 24 cases, weakly positive 64 cases) (Figure 1). Strongly positive and weakly positive groups were pooled in the positive group for association tests and survival analysis. In association analysis of immunoreactivity of each protein and pathological parameter, significant association was only found between FADD expression and $\mathrm{T}$ stage $(P=0.046)$. Neither TMEM16A nor PPFIA1 showed significant association with any pathological parameters studied (Table 3). To see if the expressions of the three genes are associated, we calculated correlation of coefficient of each expression. TMEM16A and PPFIA1 expression was marginally correlated $(r=0.6)$. However, FADD expression showed low correlation with PPFIA1 and TMEM16A expression $(\mathrm{r}=0.35$, each $)$.

\section{Disease-free survival analysis}

Survival difference was significant in grade $(P=0.01)$ and $\mathrm{N}$ stage $(P=0.00)$ but not in age $(P=0.85)$ and $\mathrm{T}$ stage $(P=0.189)$. Both PPFIA1 and TMEM16A expression showed tendency of association with poor survival group ( $P=0.161$ and 0.114 , respectively). However, the survival differences were not strong enough to show statistical significance. For FADD expression, positive expression showed a tendency towards better survival, but this also failed to show statistical significance $(P=0.182)$.

\section{Combined effect of TMEM16A, PPFIA1, and FADD expressions}

To evaluate net effect of the closely located genes, the score representing combined effect of the three gene expressions was calculated and we named it 'hazard score'. Because FADD expression showed a tendency towards better patient survival, we calculated a combined score using the following equation:

hazard score $=$ TMEM16A score + PPFIA1 score - FADD score

We found the hazard score was associated with perineural invasion status of the cases (Table 3). The cases with the hazard scores of 2 or more showed significant association with poor disease-free survival $(P=0.034$, Figure 2).

\section{Discussion}

In the current study, we screened the expressions of TMEM16A, FADD, and PPFIA1 in invasive ductal carcinoma of the breast. To see the clinical implications of these gene expressions, we analyzed the relationship between the expressions and clinical parameters, including disease-free survival. As a result, we found that FADD expression was associated with $\mathrm{T}$ stage, showed a combined score of TMEM16A, FADD, and PPFIA1 expressions and 


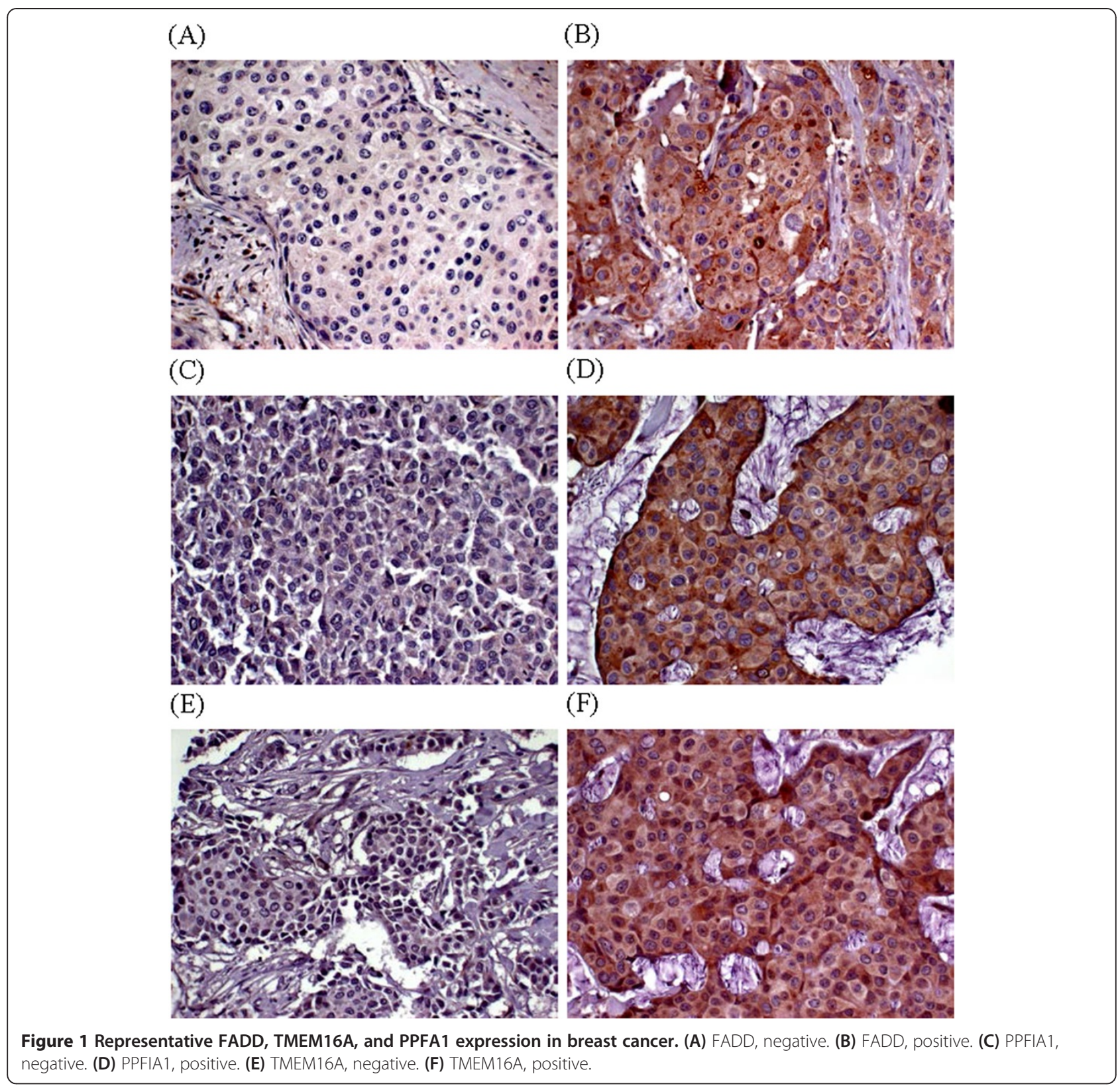

was associated with perineural invasion and disease-free survival in the invasive ductal carcinoma cases.

According to the previous reports, high expression of FADD was associated with factors indicating poor prognosis in squamous cell carcinoma of the head and neck $[14,27]$ and oral squamous cell carcinoma [28]. However, contradictory clinical associations of FADD expression were also reported. Colorectal cancer cell growth was inhibited by FADD expression [29] and high FADD expression after neoadjuvant breast cancer treatment was associated with a good prognosis group in breast cancer [30]. This may be due to the difference in cancer type or primary site from which the tumor has arisen. We found that FADD-positive cases showed a tendency towards better prognosis, which is concordant with the claim that high FADD expression is associated with better prognosis in breast cancer treatment. This also justifies subtraction of FADD score from the sum of TMEM16A and PPFIA1 scores when we calculate the hazard score of the three gene expressions in this study. Because the hazard score was associated with perineural invasion status of invasive ductal cancer of the breast, we may speculate that combination of TMEM16A, FADD and PPFIA1 expressions influence the invasiveness of the tumor cells and affect the 
Table 3 TMEM16A, FADD, and PPFIA1 expressions in invasive ductal carcinoma in relation to clinicopathological parameters ( $\mathbf{n}=$ number of cases)

\begin{tabular}{|c|c|c|c|c|c|c|c|c|c|c|c|c|}
\hline & & MEM & & & $\mathrm{FAL}$ & & & PPF & & & zard s & \\
\hline & + & - & $P$ & + & - & $P$ & + & - & $P$ & $<2$ & $\geq 2$ & $P$ \\
\hline T stage & & & 0.284 & & & $0.046^{d}$ & & & 0.444 & & & 0.069 \\
\hline 1 & 22 & 1 & & 19 & 4 & & 22 & 1 & & 20 & 3 & \\
\hline 2 to 3 & 64 & 11 & & 43 & 32 & & 66 & 9 & & 50 & 25 & \\
\hline N stage & & & 0.756 & & & 0.277 & & & 1 & & & 0.316 \\
\hline 0 & 37 & 4 & & 29 & 12 & & 37 & 4 & & 32 & 9 & \\
\hline 1 to 3 & 49 & 8 & & 33 & 24 & & 51 & 6 & & 38 & 19 & \\
\hline Grade & & & 0.756 & & & 0.285 & & & 1 & & & 0.197 \\
\hline 1 to 2 & 48 & 8 & & 38 & 18 & & 50 & 6 & & 43 & 13 & \\
\hline 3 & 36 & 4 & & 22 & 18 & & 36 & 4 & & 25 & 15 & \\
\hline$\overline{E R}$ & & & 0.724 & & & 0.576 & & & 0.439 & & & 1.000 \\
\hline 0 & 22 & 4 & & 15 & 11 & & 22 & 4 & & 19 & 7 & \\
\hline 1 & 56 & 7 & & 42 & 21 & & 58 & 5 & & 45 & 18 & \\
\hline$P R$ & & & 0.266 & & & 1.000 & & & 0.244 & & & 0.898 \\
\hline 0 & 19 & 5 & & 15 & 9 & & 20 & 4 & & 18 & 6 & \\
\hline 1 to 3 & 59 & 6 & & 42 & 23 & & 60 & 5 & & 46 & 19 & \\
\hline HER2 & & & 1.000 & & & 0.918 & & & 1.000 & & & 0.831 \\
\hline 0 & 46 & 7 & & 33 & 20 & & 47 & 6 & & 37 & 16 & \\
\hline 1 to 3 & 31 & 4 & & 23 & 12 & & 32 & 3 & & 26 & 9 & \\
\hline Age & & & 0.758 & & & 1.000 & & & 0.723 & & & 0.453 \\
\hline$<50$ & 51 & 8 & & 37 & 22 & & 54 & 5 & & 40 & 19 & \\
\hline$\geq 50$ & 35 & 4 & & 25 & 14 & & 34 & 5 & & 30 & 9 & \\
\hline$\overline{\mathrm{LVI}^{a}}$ & & & 1.000 & & & 0.746 & & & 0.716 & & & 0.564 \\
\hline 0 & 26 & 3 & & 17 & 12 & & 27 & 2 & & 19 & 10 & \\
\hline 1 to 2 & 58 & 7 & & 42 & 23 & & 58 & 7 & & 48 & 17 & \\
\hline$\overline{\mathrm{PNI}^{\mathrm{b}}}$ & & & 0.682 & & & 0.077 & & & 0.678 & & & $0.022^{a}$ \\
\hline 0 & 62 & 9 & & 48 & 23 & & 63 & 8 & & 16 & 55 & \\
\hline 1 & 18 & 1 & & 8 & 11 & & 18 & 1 & & 10 & 9 & \\
\hline
\end{tabular}

aLymphatic vessel invasion.

${ }^{b}$ Perineural invasion.

${ }^{\mathrm{C}}$ Hazard score $=$ TMEM16A score + PPFIA1 score - FADD score.

${ }^{\mathrm{d}} \mathrm{P}<0.05$.

$E R$, estrogen receptor; HER2, human epidermal growth factor; PR, progesterone receptor.

ultimate prognosis of these cases. In vitro study at molecular level is required to confirm this possibility.

PPFIA1 is required for the migration and invasion of breast cancer cell lines [23]. However, as far as we know, prognostic significance of PPFIA1 expression in breast cancer has not been evaluated to date. PPFIA1 amplification was only reported to have significant association with poor prognosis in ER-positive cancer and PPFIA1 expression in terms of prognosis was not studied [31]. In this study, we showed that PPFIA1 expression showed a tendency towards an association with poor prognosis.
In addition to PPFIA1, significance of TMEM16A expression in breast cancer has not been studied to date. Here, we showed that TMEM16A expression also showed a tendency towards an association with poor prognosis as with PPFIA1. Although the individual gene expressions failed to show statistical significance of association, the combined effect of TMEM16A, FADD, and PPFIA1 gene expression was significantly associated with disease-free survival.

The regulatory mechanism of gene expressions between PPFIA1, FADD, and TMEM16A is not known. We cannot explain causal relationship between PPFIA1, FADD, and 

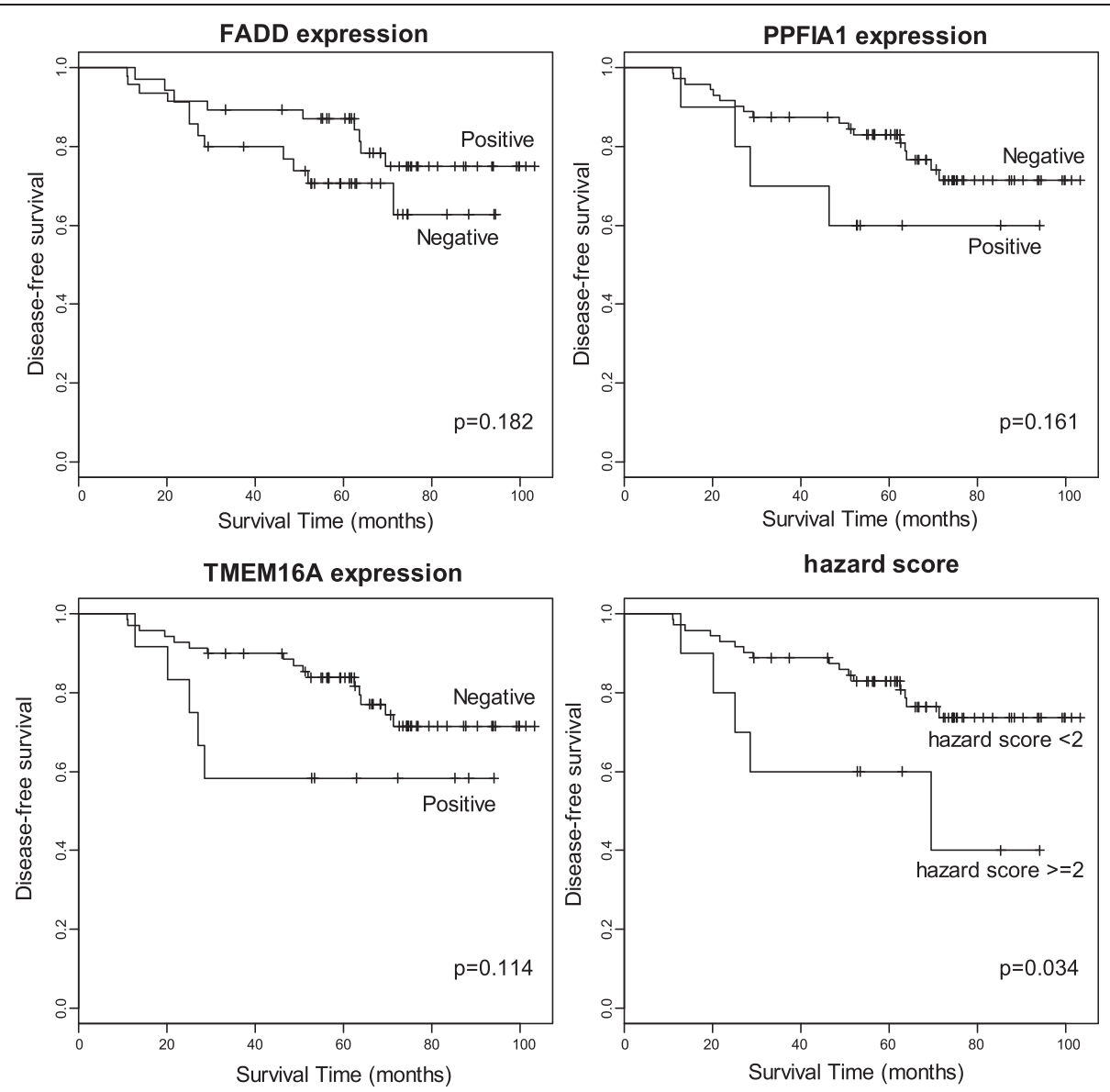

Figure 2 Disease-free survivals between groups with different expressions of FADD, PPFIA1, TMEM16A, and hazard score*.

*Hazard score $=$ TMEM16A score + PPFIA1 score - FADD score.

TMEM16A with our results in this study. However, we showed that combined expression status was associated with the disease-free survival in breast cancer. An explanation for this may be that the three genes located in the same amplification locus interact each other and influence tumor cell behavior in breast cancer; this effect resulting in the difference in disease-free survival.

An evaluation strategy of combining two or more gene alterations to analyze clinical significance can be found in several studies on human malignancies. Studies on the combination effects of two or more gene amplifications in $11 \mathrm{q} 13$ were conducted in oral squamous cell carcinoma [32] and breast cancer [31]. This method takes into account possible unknown interactions of other genes and strengthens statistical power in relatively small study sizes. Because every single gene expression is more or less affected by other gene expressions, studies on combination effects of gene expressions may be closer to biological phenomenon occurring in vivo than studies on single gene effects.

\section{Conclusion}

In summary, we screened TMEM16A, FADD, and PPFIA1 expression in breast cancer and found that combination of the three gene expressions was associated with disease-free survival in invasive ductal carcinoma of the breast.

\section{Abbreviations}

LVI: Iymphatic vessel invasion; PNI: perineural invasion; ER: estrogen receptor; PR: progesterone receptor.

\section{Competing interests}

The authors declare that we have no competing interests, financial or otherwise.

\section{Authors' contributions}

EJC performed the immunohistochemical staining, data collection and drafted the manuscript. JAY and SJ participated in the immunohistochemical staining. EKJ and HSW collected clinicopathological data. YHK collected the cases of invasive ductal carcinoma. SYK designed the study, analyzed the data and finalized the manuscript.

\section{Acknowledgments}

This research was supported by Basic Science Research Program through the National Research Foundation of Korea (NRF) funded by the Ministry of Education, Science and Technology (2012R1A1A2042078). 


\section{Author details}

'Department of Pathology, The Catholic University of Korea, School of Medicine, Seochogu Banpodaero 222, Seoul 137-701, South Korea.

${ }^{2}$ Department of Internal Medicine, The Catholic University of Korea, School of Medicine, Seoul, South Korea.

Received: 17 December 2013 Accepted: 20 April 2014

Published: 1 May 2014

\section{References}

1. Alberts B, Wilson JH, Hunt T: Molecular Biology of the Cell. 5th edition. New York: Garland Science; 2008.

2. Peters G, Fantl V, Smith R, Brookes S, Dickson C: Chromosome 11q13 markers and D-type cyclins in breast cancer. Breast Cancer Res Treat 1995, 33:125-135.

3. Karlseder J, Zeillinger R, Schneeberger C, Czerwenka K, Speiser P, Kubista E, Birnbaum D, Gaudray P, Theillet C: Patterns of DNA amplification at band q13 of chromosome 11 in human breast cancer. Genes Chromosomes Cancer 1994, 9:42-48.

4. Gaffey MJ, Frierson HF Jr, Williams ME: Chromosome 11q13, c-erbB-2, and c-myc amplification in invasive breast carcinoma: clinicopathologic correlations. Mod Pathol 1993, 6:654-659.

5. Shi ZZ, Jiang YY, Hao JJ, Zhang Y, Zhang TT, Shang L, Liu SG, Shi F, Wang MR: Identification of putative target genes for amplification within 11q13.2 and $3 q 27.1$ in esophageal squamous cell carcinoma. Clin Trans/ Oncol 2013 Epub ahead of print.

6. Meredith SD, Levine PA, Burns JA, Gaffey MJ, Boyd JC, Weiss LM, Erickson NL, Williams ME: Chromosome 11q13 amplification in head and neck squamous cell carcinoma. Association with poor prognosis. Arch Otolaryngol Head Neck Surg 1995, 121:790-794

7. Williams ME, Gaffey MJ, Weiss LM, Wilczynski SP, Schuuring E, Levine PA: Chromosome 11Q13 amplification in head and neck squamous cell carcinoma. Arch Otolaryngol Head Neck Surg 1993, 119:1238-1243.

8. Jarmuz-Szymczak M, Pelinska K, Kostrzewska-Poczekaj M, Bembnista E, Giefing M, Brauze D, Szaumkessel M, Marszalek A, Janiszewska J, Kiwerska K Bartochowska A, Grenman R, Szyfter W, Szyfter K: Heterogeneity of 11q13 region rearrangements in laryngeal squamous cell carcinoma analyzed by microarray platforms and fluorescence in situ hybridization. Mol Biol Rep 2013, 40:4161-4171.

9. Blessmann M, Al-Dam A, Hanken H, Assaf AT, Riecke B, Klatt J, Simon R, Sauter G, Heiland M, Kluwe L, Grobe A: Amplification of the PPFIA1 gene region on 11 q13 in oral squamous cell carcinomas (OSCC). J Craniomaxillofac Surg 2013, 41:845-849.

10. Rosa-Rosa JM, Pita G, Gonzalez-Neira A, Milne RL, Fernandez V, Ruivenkamp C, van Asperen CJ, Devilee P, Benitez J: A 7 Mb region within 11q13 may contain a high penetrance gene for breast cancer. Breast Cancer Res Treat 2009, 118:151-159.

11. Gibcus JH, Menkema L, Mastik MF, Hermsen MA, de Bock GH, van Velthuysen ML, Takes RP, Kok K, Alvarez Marcos CA, van der Laan BF, van den Brekel MW, Langendijk JA, Kluin PM, van der Wal JE Schuuring E: Amplicon mapping and expression profiling identify the Fas-associated death domain gene as a new driver in the 11q13.3 amplicon in laryngeal/pharyngeal cancer. Clin Cancer Res 2007, 13:6257-6266

12. Schneider $P$, Thome M, Burns K, Bodmer IL, Hofmann K, Kataoka T, Holler N Tschopp J: TRAIL receptors 1 (DR4) and 2 (DR5) signal FADD-dependent apoptosis and activate NF-kappaB. Immunity 1997, 7:831-836.

13. Chaudhary PM, Eby M, Jasmin A, Bookwalter A, Murray J, Hood L: Death receptor 5, a new member of the TNFR family, and DR4 induce FADD-dependent apoptosis and activate the NF-kappaB pathway. Immunity 1997, 7:821-830.

14. Pattje WJ, Melchers $\sqcup$, Slagter-Menkema L, Mastik MF, Schrijvers ML, Gibcus JH, Kluin PM, Hoegen-Chouvalova O, van der Laan BF, Roodenburg JL, van der Wal JE, Schuuring E, Langendijk JA: FADD expression is associated with regional and distant metastasis in squamous cell carcinoma of the head and neck. Histopathology 2013, 63:263-270.

15. Prapinjumrune C, Morita K, Kuribayashi Y, Hanabata Y, Shi Q, Nakajima Y, Inazawa J, Omura K: DNA amplification and expression of FADD in oral squamous cell carcinoma. J Oral Pathol Med 2009, 39:525-532.

16. Chen G, Bhojani MS, Heaford AC, Chang DC, Laxman B, Thomas DG, Griffin LB, Yu J, Coppola JM, Giordano TJ, Lin L, Adams D, Orringer MB, Ross BD, Beer DG,
Rehemtulla A: Phosphorylated FADD induces NF-kappaB, perturbs cell cycle, and is associated with poor outcome in lung adenocarcinomas. Proc Natl Acad Sci U S A 2005, 102:12507-12512.

17. Katoh M: Comparative genomics on mammalian Fgf3-Fgf4 locus. Int J Oncol 2005, 27:281-285.

18. Duvvuri U, Shiwarski DJ, Xiao D, Bertrand C, Huang X, Edinger RS, Rock JR, Harfe BD, Henson BJ, Kunzelmann K, Schreiber R, Seethala RS, Egloff AM, Chen X, Lui WW, Grandis JR, Gollin SM: TMEM16A induces MAPK and contributes directly to tumorigenesis and cancer progression. Cancer Res 2012, 72:3270-3281.

19. Caputo A, Caci E, Ferrera L, Pedemonte N, Barsanti C, Sondo E, Pfeffer U, Ravazzolo R, Zegarra-Moran O, Galietta L: TMEM16A, a membrane protein associated with calcium-dependent chloride channel activity. Science 2008, 322:590-594

20. West RB, Corless $\mathrm{CL}$, Chen $\mathrm{X}$, Rubin BP, Subramanian S, Montgomery $\mathrm{K}$ Zhu S, Ball CA, Nielsen TO, Patel R, Goldblum JR, Brown PO, Heinrich MC, van de Rijn M: The novel marker, DOG1, is expressed ubiquitously in gastrointestinal stromal tumors irrespective of KIT or PDGFRA mutation status. Am J Pathol 2004, 165:107-113.

21. Stanich JE, Gibbons SJ, Eisenman ST, Bardsley MR, Rock JR, Harfe BD, Ordog T, Farrugia G: Ano1 as a regulator of proliferation. Am J Physiol Gastrointest Liver Physiol 2011, 301:G1044-G1051.

22. Britschgi A, Bill A, Brinkhaus H, Rothwell C, Clay I, Duss S, Rebhan M, Raman P, Guy CT, Wetzel K, George E, Popa MO, Lilley S, Choudhury H, Gosling M, Wang L, Fitzgerald S, Borawski J, Baffoe J, Labow M, Gaither LA, Bentires-Alj M: Calcium-activated chloride channel ANO1 promotes breast cancer progression by activating EGFR and CAMK signaling. Proc Natl Acad Sci U S A 2013, 110:E1026-E1034.

23. Astro V, Asperti C, Cangi MG, Doglioni C, de Curtis I: Liprin-alpha1 regulates breast cancer cell invasion by affecting cell motility, invadopodia and extracellular matrix degradation. Oncogene 2011, 30:1841-1849.

24. Shen JC, Unoki M, Ythier D, Duperray A, Varticovski L, Kumamoto K, Pedeux R, Harris CC: Inhibitor of growth 4 suppresses cell spreading and cell migration by interacting with a novel binding partner, liprin alpha1. Cancer Res 2007, 67:2552-2558.

25. Tan KD, Zhu Y, Tan HK, Rajasegaran V, Aggarwal A, Wu J, Wu HY, Hwang J, Lim DT, Soo KC, Tan P: Amplification and overexpression of PPFIA1, a putative 11q13 invasion suppressor gene, in head and neck squamous cell carcinoma. Genes Chromosomes Cancer 2008, 47:353-362.

26. Kim Yl, Lee A, Lee BH, Kim SY: Prognostic significance of syndecan-1 expression in cervical cancers. J Gynecol Oncol 2011, 22:161-167.

27. Rasamny JJ, Allak A, Krook KA, Jo VY, Policarpio-Nicolas ML, Sumner HM, Moskaluk CA, Frierson HF Jr, Jameson MJ: Cyclin D1 and FADD as biomarkers in head and neck squamous cell carcinoma. Otolaryngol Head Neck Surg 2012, 146:923-931.

28. Prapinjumrune C, Morita K, Kuribayashi Y, Hanabata Y, Shi Q, Nakajima Y, Inazawa J, Omura K: DNA amplification and expression of FADD in oral squamous cell carcinoma. J Oral Pathol Med 2010, 39:525-532.

29. Wang QR, Yao XQ, Wen G, Fan Q, Li YJ, Fu XQ, Li CK, Sun XG: Apigenin suppresses the growth of colorectal cancer xenografts via phosphorylation and up-regulated FADD expression. Oncol Lett 2011, 2:43-47.

30. Trrdik D, Skalova H, Dundr P, Povysil C, Velenska Z, Berkova A, Stanek L, Petruzelka L: Apoptosis - associated genes and their role in predicting responses to neoadjuvant breast cancer treatment. Med Sci Monit 2012. 18:BR60-BR67.

31. Dancau AM, Wuth L, Waschow M, Holst F, Krohn A, Choschzick M Terracciano L, Politis S, Kurtz S, Lebeau A, Friedrichs K, Wencke K, Monni O, Simon R: PPFIA1 and CCND1 are frequently coamplified in breast cancer. Genes Chromosomes Cancer 2010, 49:1-8.

32. Sugahara $K$, Michikawa $Y$, Ishikawa $K$, Shoji $Y$, Iwakawa M, Shibahara T, Imai T: Combination effects of distinct cores in 11q13 amplification region on cervical lymph node metastasis of oral squamous cell carcinoma. Int J Oncol 2011, 39:761-769.

doi:10.1186/1477-7819-12-137

Cite this article as: Choi et al:: Prognostic significance of TMEM16A

PPFIA1, and FADD expression in invasive ductal carcinoma of the breast. World Journal of Surgical Oncology 2014 12:137. 